fer by infiltration of adult Arabidopsis thaliana plants. C. R. Acad. Sci. (Paris) 316:1194-1199.

2.Devic, M., S. Albert, M. Delseny, and T.J. Roscoe. 1997. Efficient PCR walking on plan genomic DNA. Plant Physiol. Biochem. 35:331-339.

3.Doyle, J.J. and J. L Doyle. 1990. Isolation of plant DNA from fresh tissue. Focus 12:13-15.

4.Frey, M., C. Stettner, and A. Gierl. 1998. General method for gene isolation in tagging approaches: Amplification of insertion mutagenised sites AIMS. Plant J. 13:717-721.

5.Liu, Y., N. Mitsukawa, T. Oosumi, and R.F. Whittier. 1995. Efficient isolation and mapping of Arabidopsis thaliana T-DNA insert junctions by thermal asymmetric interlaced PCR. Plant J. 8:457-463.

6.Ochman, H., A.S. Gerber, and D.L. Hartl. 1988. Genetic applications of an inverse polymerase chain reaction. Genetics 120:621-623.

7.Siebert, P.D., A. Chenchick, D.E. Kellog, K. Lukyanov, and S.A. Lukyanov. 1995. An improved PCR method for walking in uncloned genomic DNA. Nucleic Acids Res. 23:1087-1088

8.Spertini D., C. Béliveau, and G. Bellemare. 1999. Screening of transgenic plants by am plification of unknown genomic DNA flanking T-DNA. BioTechniques 27:308-314.

S.B. and B.D. have contributed equally to this work. Sophie Villatoux is acknowledged for technical assistance. We are grateful to $V$. Guyon and $H$. North for critical reading of the manuscript. This work was supported by Génoplante, a French plant genomics initiative. Address correspondence to Loïc Lepiniec, Laboratoire de Biologie des Semences INRA-INA PG, INRA, Centre de Versailles, Route de St Cyr, F-78026 Versailles CEDEX, France. email:lepiniec@versailles.inra.fr

Received 12 June 2000; accepted 21 November 2000.

\begin{tabular}{|c|}
\hline 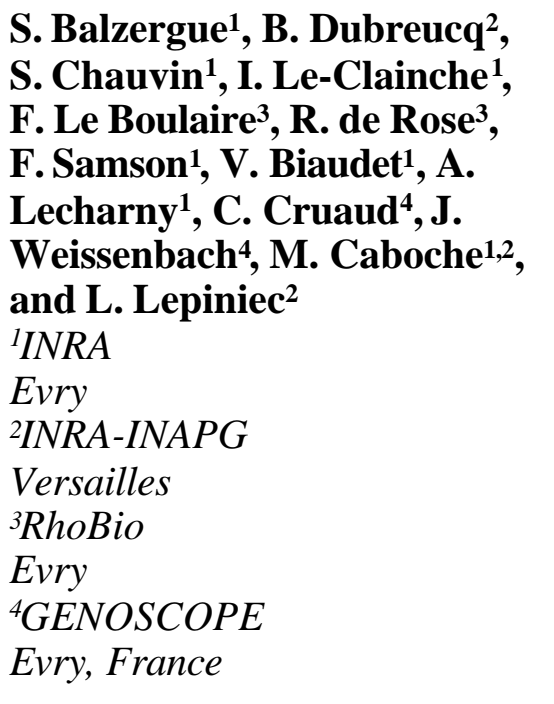 \\
\hline
\end{tabular}
S. Chauvin ${ }^{1}$, I. Le-Clainche ${ }^{1}$, F. Le Boulaire 3 , R. de Rose ${ }^{3}$, F. Samson', V. Biaudet', A. Lecharny $^{1}$, C. Cruaud ${ }^{4}$, J. Weissenbach ${ }^{4}$, M. Caboche ${ }^{1,2}$, and L. Lepiniec ${ }^{2}$

${ }^{1}$ INRA

Evry

2INRA-INAPG

Versailles

${ }^{3}$ RhoBio

${ }^{4}$ GENOSCOPE

Evry, France

\section{Use of Fluorescently Labeled DNA and a Scanner for Electro- phoretic Mobility Shift Assays}

BioTechniques 30:504-508 (March 2001)

The electrophoretic mobility shift assay (EMSA) is commonly used to determine the presence of specific transcription factors within the nucleus. In this assay, nuclear extracts from cells are mixed with a radioactively labeled oligonucleotide or DNA fragment containing a sequence known to bind to the transcription factor. This mixture is then electrophoresed through a non-denaturing acrylamide gel, and the gel is subjected to autoradiography. Binding of the oligonucleotide, and hence the presence of the transcription factor, is evidenced by a change or shift in the migration of the oligonucleotide. This method is quite sensitive but has the drawback that it relies on the labeling of DNA with a radioisotope. These probes are short lived, require special precautions for handling and disposal, and pose the health risk associated with the use of radioisotopes. To overcome these problems, we wanted to determine if a fluorescently labeled oligonucleotide could be used in an EMSA.

To determine if non-isotopic methods could be used to detect the binding of $\mathrm{NF}-\kappa \mathrm{B}$, several oligonucleotides were obtained from commercial sources (Research Genetics, Huntsville AL, USA) (Table 1). Oligo 1 contained the fluorescent dye, carboxyfluorescein (FAM) at the $5^{\prime}$ end, while Oligo 1 unlabeled, which had the same sequence and therefore serves as a competitor for Oligo 1, was not fluorescently tagged. Oligo 1 complement binds to Oligo 1 and Oligo 1 unlabeled. To create an oligonucleotide that would not serve as a competitive inhibitor for NF- $\kappa \mathrm{B}$ binding to Oligo 1, we synthesized a mutated version (and its complement) of the unlabeled oligonucleotide. Mutated Oligo 1 contained two point mutations that have been previously shown to abolish NF- $\kappa \mathrm{B}$ binding (1).

Nuclear extracts were prepared as described previously (2). U-87 MG cells were seeded onto $150-\mathrm{mm}$ culture plates and allowed to become approximately $80 \%$ confluent. Cells were removed from the plates by trypsinization and recovered by centrifugation at $2000 \times g$ for $5 \mathrm{~min}$. The supernatant was discarded, and cells were washed in 1 mL buffer A [10 mM HEPES, pH 7.9, $1.5 \mathrm{mM} \mathrm{MgCl}_{2}, 10 \mathrm{mM} \mathrm{KCl}, 0.1 \%$ Nonidet $^{\mathrm{TM}} \mathrm{P}-40$ (NP-40), and $0.5 \mathrm{mM}$ dithiothreitol (DTT)] and pelleted at $2000 \times g$ for $5 \mathrm{~min}$. The supernatant was again discarded, and cells were resuspended by gentle pipetting in $80 \mu \mathrm{L}$ buffer A containing $0.1 \%$ Triton ${ }^{\circledR} \mathrm{X}$ 100. After incubation at $4^{\circ} \mathrm{C}$ for 10 $\mathrm{min}$, the homogenate was centrifuged at $2000 \times g$ for $5 \mathrm{~min}$, and the nuclear pellet was washed in $60 \mu \mathrm{L} 20 \mathrm{mM}$ HEPES, pH 7.9, $0.42 \mathrm{M} \mathrm{NaCl}, 25 \%$ (v/v) glycerol, $1.5 \mathrm{mM} \mathrm{MgCl}_{2}$, and 0.2 mM EDTA. This suspension was incubated on ice for $30 \mathrm{~min}$ and then centrifuged at $16000 \times g$ for $20 \mathrm{~min}$ at $4^{\circ} \mathrm{C}$. The supernatant, which represented the nuclear extract, was stored at $-80^{\circ} \mathrm{C}$ until use. Total protein concentrations of the extracts were determined using the bicinchoninic acid (BCA) assay (Pierce Chemical, Rockford, IL, USA) using bovine serum albumin (BSA) as the standard.

Assays were performed in $40-\mu \mathrm{L}$ volumes containing $20 \mu \mathrm{g}$ nuclear protein incubated with 1 pmol Oligo 1 and its complement in binding buffer (10 $\mathrm{mM}$ HEPES, $50 \mathrm{mM} \mathrm{KCl}, 2.5 \mathrm{mM}$ DTT, $0.2 \mathrm{mM}, 0.05 \%$ NP-40, $10 \%$ glycerol, $\mathrm{pH}$ 7.9) for $30 \mathrm{~min}$ at room tem perature. Competition experiments were performed by mixing Oligo 1 and its complement and $50 \mathrm{pmol}$ of the oligonucleotides used for competition. The supershift assays were performed by adding $0.5 \mathrm{pmol}$ antibody to the $\mathrm{p} 65$

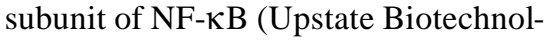
ogy, Lake Placid, NY, USA) to reactions that contained Oligo 1 and its complement as well as nuclear extract. Samples were loaded on a $7 \%$ native polyacrylamide gel, and electrophoresis was performed in $50 \mathrm{mM}$ Tris, $\mathrm{pH}$ $8.3,380 \mathrm{mM}$ glycine. Following electrophoresis, the gel was analyzed by blue-excited fluorescence scanning with an 860 Storm $^{\mathrm{TM}}$ FluorImager (Amersham Pharmacia Biotech, Piscataway, NJ, USA). 


\section{Benchmarks}

Table 1. Sequences of the Oligonucleotides Used

\begin{tabular}{|c|c|}
\hline Oligo 1 & 5'-FAM-CATGAACCGGGAATTTCCAACATG-Dabcyl-3' \\
\hline $\begin{array}{l}\text { Oligo } 1 \\
\text { Complement }\end{array}$ & 5'-AATTGGAAATTCCCGGTTCC-3' \\
\hline Oligo 1 Unlabeled & 5'-CATGAACCGGGAATTTCCAACATG-3' \\
\hline Mutated Oligo 1 & 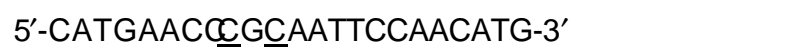 \\
\hline $\begin{array}{c}\text { Mutated Oligo } 1 \\
\text { Complement }\end{array}$ & 5'-AATTGGAAATT GCGGGGTTCC-3' \\
\hline AP-1 & BODIPY 630/650-5'-CGCTTGATGAGTCAGCCGGAA-3' \\
\hline AP-1 Complement & 5'-TTCCGGCTGACTCATCAAGCG-3' \\
\hline
\end{tabular}

As can be seen in Figure 1, protein from the extract was able to cause a shift in the migration of the oligonucleotide, and this shift could be inhibited by excess unlabeled oligonucleotide but not by the oligonucleotide that contained the two point mutations. This shift was due to the association of NF- $\kappa \mathrm{B}$ proteins with the oligonucleotide because an increase in the apparent molecular weight of the complex occurred when the antibody to p65 was present. There was no shifted band without the addition of the extract (data not shown). This data demonstrated that these fluorescently labeled oligonu-

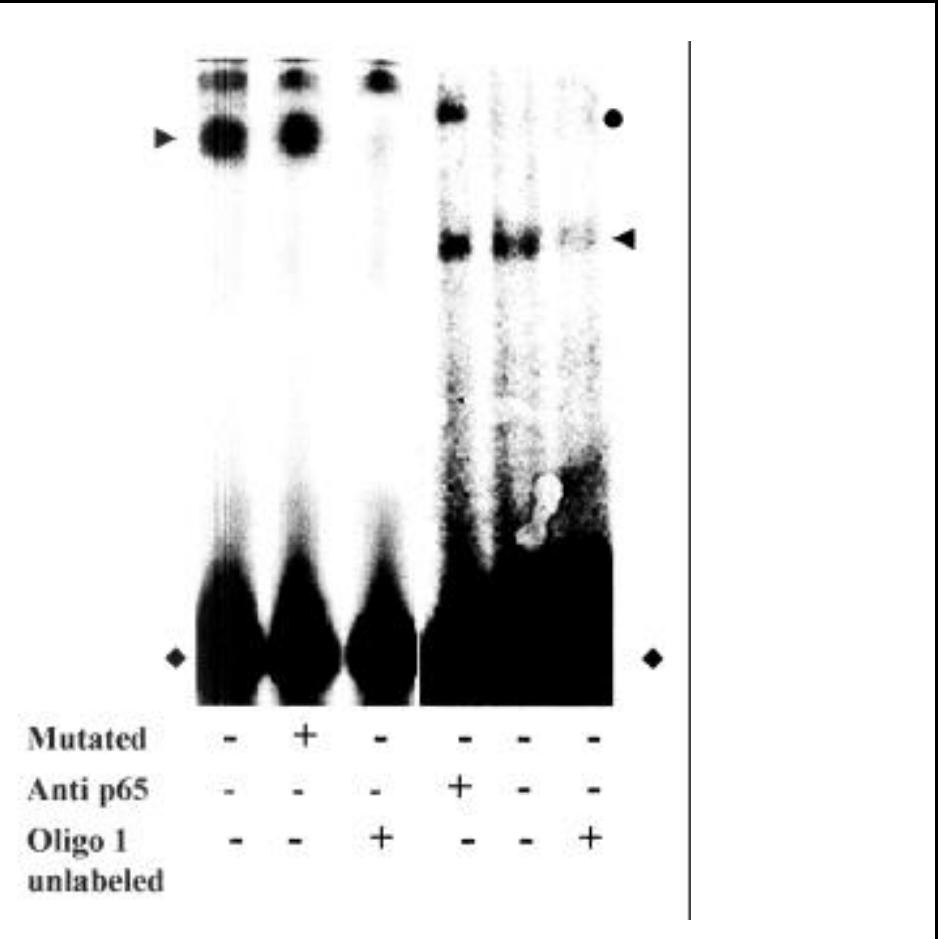

Figure 1. EMSA performed with extracts of U-87 MG tumor cells. Extracts were prepared from U$87 \mathrm{MG}$ glioblastomas as described in the text, and $20 \mu \mathrm{g}$ were used for EMSAs. All assays contained nuclear extract and the NF-KB binding oligonucleotides Oligo 1 and its complement. The diamonds indicate the unshifted oligonucleotides, while the arrows indicate the shifted oligonucleotides and the circle indicates the position of the supershifted oligonucleotides. 


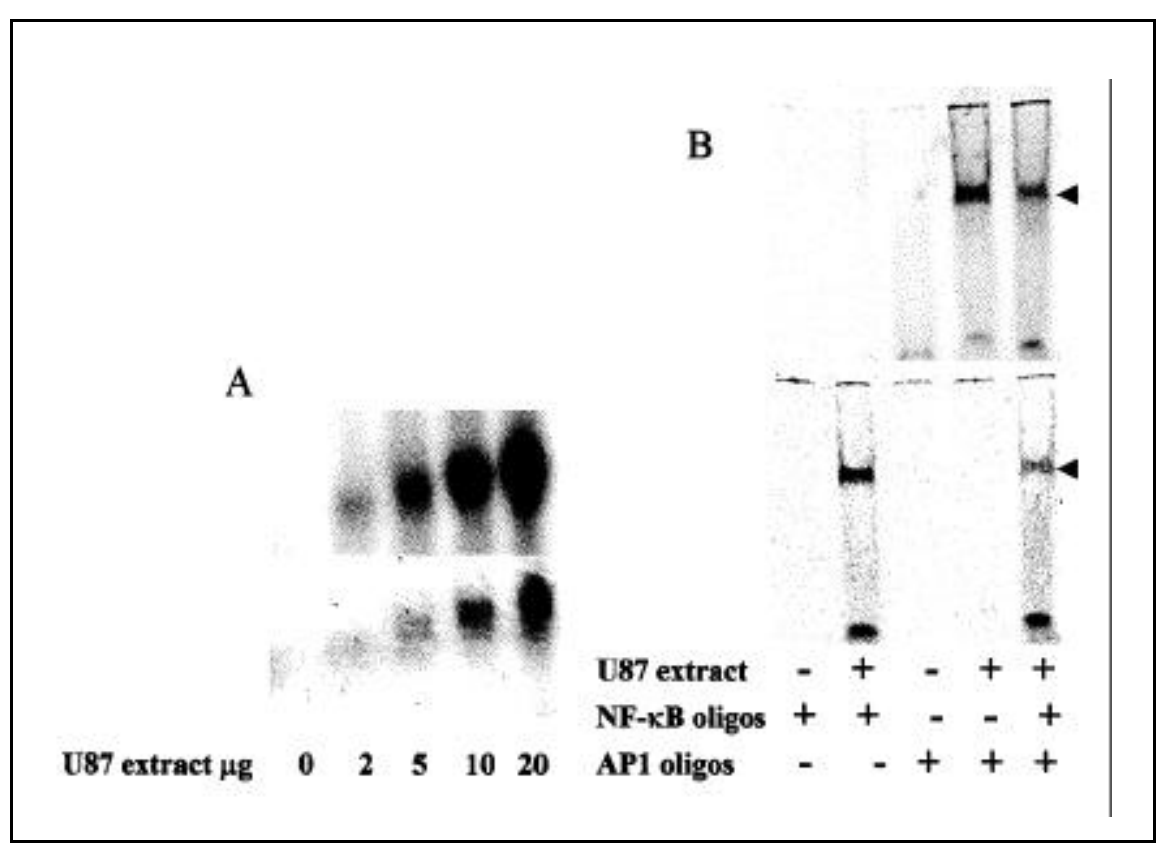

Figure 2. EMSAs comparing the sensitivity of oligonucleotides labeled with fluorescence and radioisotope and multiplexing. (A) Different amounts of the U-87MG extracts were incubated with the fluorescently labeled AP-1 oligonucleotide and the complement of this oligonucleotide that had been end labeled with ${ }^{32} \mathrm{P}$ as described. The upper panel shows the image from the isotope detection, while the lower panel shows the image from the fluorescent detection. (B) Multiplex analysis using both the $\mathrm{NF}-\kappa \mathrm{B}$ oligonucleotides and the AP-1 oligonucleotides. The upper panel is the image from the red excited fluorescence (BODIPY630/650, AP-1)-labeled oligonucleotide, while the lower panel is from the scan performed with the blue excited fluorescence (FAM, NF- $\mathrm{KB}$ ).

cleotides could be used for EMSAs.

As EMSAs are commonly performed with radioactively labeled oligonucleotides, we were interested in the relative sensitivity of a fluorescently labeled oligonucleotide as compared to a radioactively labeled oligonucleotide. We obtained an oligonucleotide that contained the binding site for the transcription factor AP-1 that was conjugated to the dye BODIPY ${ }^{\circledR} 630 / 650$ (Life Technologies, Rockville, MD, USA). The complement for this oligonucleotide was not conjugated to a fluorescent dye and was used for labeling with T4 polynucleotide kinase (New England Biolabs, Beverly, MA, USA) and $\left[\gamma_{-}{ }^{32} \mathrm{P}\right] \mathrm{ATP}$ (ICN Biomedicals, Costa Mesa, CA, USA) by standard methods (3). Purification of the oligonucleotide through a spin column indicated that it had a specific activity greater than $10^{7} \mathrm{cpm} / \mathrm{pmol}$. The radioactively labeled oligonucleotide was mixed with an equal amount of fluorescently labeled oligonucleotide and incubated with varying amounts of nuclear extract, as described above. After electrophoresis, the gel was first used to expose a phosphor storage screen for detection of the isotope and then used for direct fluorescent imaging using red excited fluorescence. The results are shown in Figure 2A. Densitometric scanning of the two images indicated that the radioactively labeled oligonucleotide had an approximately two- to threefold greater sensitivity than the fluorescently labeled oligonucleotides.

One of the potential uses of fluorescently labeled compounds would be for multiplex analysis. To determine if this would be feasible, we performed EMSA using both the NF- $\mathrm{KB}$ oligonucleotides and the AP-1 oligonucleotides. The results (Figure 2B) demonstrate that, by using two different dyes located on two different oligonucleotides, we were able to detect specific binding of each oligonucleotide within one sample.

In summary, we have demonstrated that EMSA may be performed with adequate sensitivity by using fluorescently labeled probes instead of radioactively labeled probes, thereby reducing the need for radioisotope use in the laboratory. Furthermore, the sensitivity of using fluorescently labeled oligonucleotides was slightly less than the sensitivity of using radioactively labeled oligonucleotides. Our findings are sim ilar to those recently published by Ruscher et al. (4) who demonstrated that fluorescently labeled oligonucleotides could be used for the detection of transcription factor binding using a DNA sequencer for detection. We have extended these findings to demonstrate that the technique works quite well in a polyacrylamide gel format, which is more commonly used, and that multiplex analysis can be performed on a single sample.

\section{REFERENCES}

1.Guttridge, D.C., C. Albanese, J.Y. Reuther, R.G. Pestell, and A.S.Baldwin, Jr. 1999. NF- $\kappa B$ controls growth and differentiation through transcriptional regualtion of cyclin D1. Mol. Cell. Biol. 19:5785-5799.

2.Paulose, M., B. Bennett, A. Manning, and K. Essani. 1998. Selective inhibition of TNF$\alpha$ induced cell adhesion molecule gene expression by tanapox virus Microb. Pathog. 25:33-41.

3.Sambrook, J., E.F. Fritsch, and T. Maniatis. 1989. Molecular Cloning: A Laboratory Manual, 2nd ed. CSH Laboratory Press, Cold Spring Harbor, NY.

4.Ruscher, K., M. Reuter, D. Kupper, G. Trendelburg, U. Dirnagi, and A. Meisel. 2000. A fluorescence based non-radioactive electrophoretic mobility shift assay. J. Biotechnol. 78:163-170.

This work was supported by grant no. R29CA69477 from the National Cancer Institute. The authors would like to thank Drs. Sara Ehlke-Bejcek and John Geiser for their critical reading of this manuscript. Address correspondence to Dr. Bruce Bejcek, Room 3441 Wood Hall, Department of Biological Sciences, Western Michigan University, Kalamazoo, MI 49008, USA. email:Bruce.Bejcek@wmich.edu

Received 24 May 2000; accepted 31 October 2000.

\section{Kelly Murphy, Takeshi Shimamura, and Bruce E. Bejcek Western Michigan University Kalamazoo, MI, USA}

